\title{
ACE2 modulates glucose homeostasis through GABA signaling during metabolic stress
}

\author{
Xiaoyi Ma1, Fei Gao², Qi Chen¹, Xiuping Xuan1, Ying Wang1, Hongjun Deng', Fengying Yang1 and Li Yuan¹ \\ 1Department of Endocrinology, Union Hospital, Tongji Medical College, Huazhong University of Science and Technology, Wuhan, China \\ ${ }^{2}$ Department of Orthopedic Surgery, Union Hospital, Tongji Medical College, Huazhong University of Science and Technology, Wuhan, China
}

Correspondence should be addressed to L Yuan: yuanli18cn@126.com

\begin{abstract}
The angiotensin-converting enzyme 2 (ACE2)/angiotensin 1-7 (A1-7)/MAS axis and glutamate decarboxylase 67 (GAD67)/gamma-aminobutyric acid (GABA) signal both exist in the islet and play important roles in regulating blood glucose metabolism. It has been reported that the activation of ACE2 in the brain increases GABA expression to improve biological effects; however, it is unclear whether there is functional correlation between the ACE2/A1-7/MAS axis and GAD67/GABA signal in the islet. In this study, we showed that the ACE2/A1-7/MAS and GABA signaling systems decreased in the islet of different metabolic stress models. In ACE2-knockout mice, we found that GAD67 and GABA expression decreased significantly, which was reversed by exogenous administration of A1-7. Furthermore, A1-7 mediated PDX1 and AKT activation was inhibited by allylglycine (a specific GAD67 inhibitor) in MIN6 cells. Moreover, giving A1-7 and GABA could significantly reduce beta-cell dedifferentiation and improved glucose metabolism during metabolic stress in vivo and in vitro. In conclusion, our study reveals that the ACE2/A1-7/MAS axis improves beta-cell function through regulating GAD67/GABA signal in beta cells and that up-regulating the ACE2/A1-7/MAS axis and GABA signals delays the development of obesity-induced diabetes.
\end{abstract}

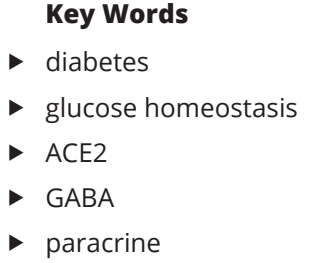

Journal of Endocrinology (2020) 246, 223-236

\section{Introduction}

Type 2 diabetes mellitus (T2DM) is characterized by progressive beta-cell dysfunction. In recent years, the incidence of prediabetes and T2DM has steadily increased (Kehlenbrink et al. 2019). Moreover, the incidence of diabetes in China has increased by more than $50 \%$ in the past decade and is estimated to increase further in the next decade (Hu \& Jia 2018, Zhou et al. 2019). Therefore, it is important to explore strategies to protect islet function and prevent the onset of T2DM in prediabetes stage.

The renin-angiotensin system (RAS) is active in pancreases and regulates islet microcirculation and beta cell function. In this regard, the angiotensin-converting enzyme 2 (ACE2)/angiotensin 1-7 (A1-7)/MAS axis has garnered close attention from researchers in recent years. ACE2 is a known positive regulator of islet function and acts on MAS receptors through its catalytic product A1-7, improving microcirculation (Yuan et al. 2013), inhibiting inflammatory responses and oxidative stress (Shi et al. 2018), thus positively regulating beta-cell function and insulin release (Yuan et al. 2014, Brar et al. 2017). In our previous studies, A1-7 was found to improve vascular endothelial growth factor (VEGF) levels in islets and reduce beta-cell dedifferentiation, thus improving glucose tolerance in mice fed with a high-fat diet (HFD) (Xuan et al. 2018). The aforementioned studies on the ACE2/A1-7/MAS axis are all based on the islet endothelial 
cell mediated theory. Interestingly, mass ACE2 in islets has been found to be expressed in alpha cells, and MAS receptors are expressed in beta cells (Brar et al. 2017, Xuan et al. 2018), suggesting that ACE2/A1-7/MAS axis may play an important role in regulating beta-cell function.

Gamma-aminobutyric acid (GABA), originally identified as an important inhibitory neurotransmitter in the mammalian CNS, plays an important role in glucose homeostasis and islet function, including insulin release (Taneera et al. 2012, Purwana et al. 2014, Wan et al. 2015, Wang et al. 2019). In beta cells, GABA is produced by the decarboxylation of glutamic acid by glutamate decarboxylase 67 (GAD67). Under physiological conditions, GABA promotes insulin secretion and betacell proliferation through autocrine pathway and also acts on alpha cells in a paracrine form to inhibit glucagon release, which exerts a hypoglycemic effect through biphasic regulation (Wan et al. 2015, Feng et al. 2017). Moreover, recent studies have found that long-term intervention in diabetic mice with GABA can promote the transdifferentiation of alpha cells into beta cells (Ben-Othman et al. 2017, Li et al. 2017). ACE2/A1-7/MAS axis has been closely associated with the regulation of GABA signal in the CNS. It has been reported that ACE2 promotes the expression of GABA through MAS receptors, improving anxiety in mice (Wang et al. 2016, Legat et al. 2018). However, whether there is a close association between ACE2 and GABA in the pancreas for metabolic stress diseases is still unknown.

In this study, we used genetic and pharmacological mouse models to explore the intrinsic relationship between the ACE2/A1-7/MAS axis and GABA in islets. We found that the ACE2/A1-7/MAS axis improves beta-cell dysfunction by regulating GAD67/GABA signal, suggesting that ACE2 plays an important role in regulating glucose metabolism through the paracrine effect between alpha and beta cells. In summary, these results could reveal a novel paracrine network in islet that regulates alpha/beta cell function in metabolic stress diseases.

\section{Materials and methods}

\section{Mice and treatments}

\section{Metabolic stress mouse models}

Six-week-old male C57BL/6J WT mice were randomly divided into three groups ( $n=5-7$ mice/group): (1) standard diet control group (SD); (2) HFD group; and (3) $\mathrm{HFD}+$ streptozotocin-treated group $(\mathrm{HFD}+\mathrm{STZ})$. Mice in the SD group were fed a standard chow diet. The HFD mice were fed a HFD (\#D12492) for 16 weeks. In the HFD +STZ group, mice were first fed a HFD for 4 weeks and then injected with STZ (30 mg/kg, Sigma-Aldrich) for 3 consecutive days to induce T2DM, as previously described (Liu et al. 2019), and the mice were continually in HFD until 16 weeks.

\section{ACE2 knockout (ACE2KO) mouse model}

Mice were divided into five groups: WT SD group, WT HFD group, ACE2KO SD group, ACE2KO HFD group, and ACE2KO HFD + A1-7 group ( $n=5$ mice/group). Sixweek-old male ACE2KO mice and age-matched male WT littermates were purchased from the Laboratory Animal Institute of the Chinese Academy of Medical Sciences and were fed a SD or HFD for 16 weeks. Mice in the ACE2KO HFD + A1-7 group were injected intraperitoneally (i.p.) with A1-7 (GL Biochem, $576 \mu \mathrm{g} / \mathrm{kg} /$ day) (Xuan et al. 2018) and those in the other four groups were injected with saline vehicle from 12 weeks to 16 weeks.

\section{A1-7 and GABA treatment models}

Six-week-old male C57BL/6J WT mice were divided into five groups ( $n=5-8$ mice/group): SD group, HFD group, A1-7 group, GABA group and $A(1-7)+$ GABA group. Except the SD group, the other four groups were fed a HFD for 16 weeks. Mice in the A1-7 group, GABA group and $A(1-7)+G A B A$ group were treated with A1-7 $(576 \mu \mathrm{g} / \mathrm{kg} / \mathrm{day}$, i.p.) (Xuan et al. 2018), GABA (Sigma, $6 \mathrm{mg} / \mathrm{mL}$ in drinking water) (Liu et al. 2017), or A1-7 plus GABA daily from 12 weeks to 16 weeks, respectively.

The study was performed in accordance with the National Institute of Health policies on the use of laboratory animals and was approved by the Animal Research Committee of Tongji Medical College, Huazhong University of Science and Technology, Wuhan, China. All mice were housed in a specific pathogen free (SPF) animal laboratory, in a $12 \mathrm{~h}$ light:12 h darkness cycle at room temperature $\left(20-22^{\circ} \mathrm{C}\right)$. Body weight of all animals was monitored once a week.

\section{Glucose metabolism and biochemical analyses}

Tail fasting blood glucose (FBG) was measured using a OneTouch glucometer (LifeScan, Canada) after mice were fasted for $16 \mathrm{~h}$. Intraperitoneal insulin tolerance tests (IPITTs) and intraperitoneal glucose tolerance tests (IPGTTs) were performed on the third batch of mice at 12 weeks and 16 weeks, as previously described (Xuan et al. 2018, Liu et al. 2019). Briefly, The IPITTs were performed in mice by injecting insulin (1 U/kg, i.p.) after fasted for 
$6 \mathrm{~h}$ and the IPGTTs were performed by the injection of glucose $(2 \mathrm{~g} / \mathrm{kg}$, i.p.) after overnight fasting, and plasma glucose was measured at different time points.

Blood samples were collected at 0 and 30 min during IPGTT experiments. After being centrifuged, the plasma samples were stored at $-80^{\circ} \mathrm{C}$. Plasma insulin and $\mathrm{A} 1-7$ concentration was evaluated using an insulin ELISA kit (MU30432 and MU30979, Bio-Swamp), as per the manufacturer's instructions. Plasma triglyceride (TG), cholesterol (TC), high density lipoprotein (HDL), and low-density lipoprotein (LDL) were determined using corresponding detection kits (Nanjing Jiancheng, China).

\section{Tissue collection}

Mice were injected with insulin $(0.75 \mathrm{U} / \mathrm{kg}$, i.p.) for 30 min prior to killing. Next, samples were collected from the epididymis white adipose tissues (eWATs), liver and pancreas. The eWATs, liver and pancreas (1/3) samples were immediately snap frozen in liquid nitrogen and stored at $-80^{\circ} \mathrm{C}$ prior to analysis. As previously reported (Feng et al. 2013), pancreatic tissues (2/3) were harvested and fixed in $4 \%$ formaldehyde overnight at room temperature (RT) for histological examination.

\section{Immunodetection}

Pancreatic tissues were serially cut into $5-\mu \mathrm{m}$ sections for hematoxylin and eosin (H\&E) staining and immunodetection. Primary antibodies were listed in Table 1 and detailed immunodetection steps were described in our previous articles (Xuan et al. 2018). There were $20-30$ islets per mouse examined ( $n=5-8$ mice/group).

\section{Isolation of pancreatic islets}

To analyze primary islet in vitro, pancreatic islets were isolated from WT C57BL/6J mice as previously described (Yoshihara et al. 2010) with minor modifications. Briefly, pancreatic tissue was isolated at $38^{\circ} \mathrm{C}$ by perfusing the pancreas with collagenase $\mathrm{P}$ (Roche, $0.5 \mathrm{mg} / \mathrm{mL}$, i.p.) through the common bile duct for $8 \mathrm{~min}$. Digested exocrine cells and intact islets were separated using Histopaque-1077 (Sigma) and by centrifugation at $900 \boldsymbol{g}$ for $15 \mathrm{~min}$. Intact islets were manually selected.

\section{Cell culture}

Islets were cultured in RPMI-1640 (HyClone) containing $11.1 \mathrm{mmol} / \mathrm{L}$ glucose, $10 \%$ fetal bovine serum

Table 1 Antibodies for immunodetection.

\begin{tabular}{l} 
Antibody \\
\hline Guinea pig anti-insulin \\
Rabbit anti-GLP-1 \\
Rabbit anti-glucagon \\
Rabbit anti-FOXO1 \\
Rabbit anti-GAD67 \\
Rabbit anti-GBR \\
Rabbit anti-OCT4 \\
Rabbit anti-GABA \\
Anti-MAS receptor \\
Goat anti-ACE2 \\
Rabbit anti-Ki67 \\
Rabbit anti-NGN3 \\
Rabbit anti-PC1/3 \\
Rabbit anti-VEGF \\
Rabbit anti-eNOS \\
Mouse-anti- $\beta$-actin \\
Rabbit anti-phospho-AKTSer473 \\
Rabbit anti-AKT \\
Rabbit anti-CREB \\
Rabbit anti-phospho-CREBSer133 \\
Rabbit anti-PDX1
\end{tabular}

\begin{tabular}{l} 
Source \\
\hline ab7842, Abcam \\
ab22625, Abcam \\
\#2760, Cell Signaling Technology (CST) \\
\#2880, CST \\
GTX101881, GeneTex \\
GTX102511, GeneTex \\
GTX101497, GeneTex \\
NBP2-43558, Novus \\
NBP1-78444, Novus \\
NBP2-67692, Novus \\
ARG53222, Arigo \\
2325032, Millipore \\
AB10553, Millipore \\
MAB751, R\&D \\
\#32027, CST \\
66009-1-lg, Proteintech \\
\#9271, CST \\
\#4691, CST \\
\#9197, CST \\
\#9198, CST \\
\#5679, CST
\end{tabular}

\begin{tabular}{l} 
Dilution \\
\hline IF: $1: 100$ \\
IF: $1: 100$ \\
IF: $1: 200$ \\
IF: $1: 200$ \\
IF: $1: 100$ \\
WB: $1: 1000$ \\
IF: $1: 100$ \\
IF: $1: 100$ \\
IF: $1: 100$ \\
IF: $1: 100$ \\
IF: $1: 200$ \\
IF: $1: 200$ \\
IF: $1: 100$ \\
WB: $1: 1000$ \\
IF: $1: 100$ \\
IHC: $1: 200$ \\
IHC: $1: 200$ \\
WB: $1: 3000$ \\
WB: $1: 1000$ \\
WB: $1: 2000$ \\
WB: $1: 1000$ \\
WB: $1: 1000$ \\
WB: $1: 1000$
\end{tabular}

ACE2, angiotensin-converting enzyme 2; CREB, CAMP-response element binding protein; eNOS, endothelial nitric oxide synthase; FOXO1, forkhead box 01; GABA, gamma-aminobutyric acid; GAD67, glutamate decarboxylase 67; GBR, GABA B receptor; GLP-1, glucagon-like peptide-1; NGN3, neurogenin 3; OCT4, octamer-binding transcription factor-4; PC1/3, prohormone convertase 1/3; PDX1, pancreatic and duodenal homeobox 1; VEGF, vascular endothelial growth factor.

\begin{tabular}{|lr} 
https://joe.bioscientifica.com & (c) 2020 Society for Endocrinology \\
https://doi.org/10.1530/JOE-19-0471 & Published by Bioscientifica Ltd. \\
Printed in Great Britain
\end{tabular}


(FBS, Gibco) and 1\% penicillin/streptomycin. MIN6, a mouse insulinoma cell line between passage 10 and 30, was purchased from the American Type Culture Collection (ATCC). For subsequent experiments, the MIN6 cells was cultured in DMEM containing $25 \mathrm{mmol} / \mathrm{L}$ glucose, $15 \% \mathrm{FBS}$ and $50 \mu \mathrm{mol} / \mathrm{L}$ beta-mercaptoethanol in a $37^{\circ} \mathrm{C}$ incubator at 5\% $\mathrm{CO}_{2}$. When the MIN6 cells reached $80 \%$ confluency, stimulations were added. Islets or MIN6 cells were cultured in corresponding medium containing $0.5 \mathrm{mmol} / \mathrm{L}$ palmitate acid (PA) for $48 \mathrm{~h}$ with or without A1-7 (10-6 mol/L), A779 (10-5 mol/L), GABA (100 $\mu \mathrm{mol} / \mathrm{L})$ or allylglycine (5 mmol/L, Sigma-Aldrich) (Wang et al. 2007, Yuan et al. 2014).

\section{Assessment of glucose stimulated insulin release (GSIS)}

For insulin secretion assays, insulin secretion in MIN6 cells and mouse islets was assayed as previously described (Ramracheya et al. 2016, Mita et al. 2017, Xuan et al. 2018). Supernatants were collected and insulin concentration determined using an ELISA kit (MU30432, Bio-Swamp, China). Insulin secretion was displayed according to the insulin stimulation index: stimulated concentration/basal insulin concentration $\times 100$ (Sharp \& Vermette 2017, Xuan et al. 2018).

\section{Real-time polymerase chain reaction (RT-PCR)}

Total RNA was extracted using TRIzol reagent (Takara) following the manufacturer's protocols. cDNA synthesis (Takara) was performed on $1 \mathrm{mg}$ of total RNA. The cDNA was then used for RT-PCR amplifications using gene-specific primers and SYBR Green RT-PCR kits (Takara). Primers used in the study were listed in Table 2. The housekeeping gene used for RT-PCR was Gapdh, which was used to normalize the expression levels of the target gene (Wang et al. 2019).

\section{Immunoblotting}

Tissues and cultured MIN6 cells were lysed in lysis buffer supplemented with phosphatase inhibitors (Roche). Immunoblotting was performed as described previously (Cheng et al. 2015). The primary antibodies were listed in Table 1 for detail.

\section{Statistical analyses}

Statistical analyses were performed using GraphPad Prism 7.0 (GraphPad Software). Student's unpaired twotailed $t$-test was performed for two-group analyses and a one-way or two-way ANOVA followed by the post hoc Tukey-Kramer test was performed for multiple group comparisons. $P$ value $<0.05$ was considered statistically significant.

\section{Results}

The expression of ACE2 and GABA decreases in islets of metabolic stress models

To assess ACE2 and GABA activity, the HFD and HFD+STZ induced T2DM mouse models were established (Supplementary Fig. 1A, see section on

Table 2 List of primers used for real-time PCR using SYBR-Green.

\begin{tabular}{ll} 
Gene & Gene ID \\
\cline { 1 - 1 } Ace2 & NM_001130513.1 \\
Mas & NM_008552.5 \\
Insulin & NM_008386.3 \\
Mafa & NM_194350.2 \\
Pro-glucagon & NM_008100.4 \\
Gad67 & NM_008077.5 \\
Nkx6.1 & NM_144955.2 \\
Pdx1 & NM_008814.3 \\
Ag2r & NM_001362655.1 \\
Aa4r & NM_001359041.1 \\
Gbr & NM_019439.3 \\
Ngn3 & NM_009719 \\
Oct4 & CNM_001252452.1 \\
Gapdh & NM_001289726.1 \\
\hline
\end{tabular}

\begin{tabular}{l} 
Forward sequence $\left(5^{\prime}\right.$ to $\left.3^{\prime}\right)$ \\
\hline TGTGACCCTGCATCTCTGTT \\
TGTGGGCACTTTCGTGCTT \\
CTGGTGCAGCACTGATCTACA \\
GAGGAGGTCATCCGACTGAAA \\
TGAATGAAGACAAACGCCACT \\
TCCGGCTTTTGGTCCTTCG \\
ACAAACCTCTGGACCCGAAC \\
TCCACCACCACCTTCCAGCTCA \\
ATGAGTTCGCCAAATACATGGAG \\
ACAATGAGACTCACCATAAGTGC \\
TGGTTTCTCATCGGGTGGTAT \\
CCAAGAGCGAGTTGGCACT \\
GGCTTCAGACTTCGCCTCC \\
AGCCTCGTCCCGTAGACAAAAT
\end{tabular}

Reverse sequence (5' to $\left.3^{\prime}\right)$

CAACTTCTGCCCAGCTTCAG AATGACTCTCTTCTCCGCTGTCA AGCGTGGCTTCTTCTACACAC GCACTTCTCGCTCTCCAGAAT CCACTGCACAAAATCTTGGGC ATGCCGCCCGTGAACTTTT AATAGTAAAGGCCCGGCGAG AATTCCTTCTCCAGCTCCAG GGAGCAGAATCCACAGCGT GGCCTTTGGTCCAGGTGTAG CCAAGGCCCAGATAGCATCA CGGGCCATAGAAGCTGTGG AACCTGAGGTCCACAGTATGC CCGTGAGTGGAGTCATACTGGA

Aa4r, alpha 4 subunit of type A GABA receptor; Ag2r, g2 subunit of type A GABA receptor; Gapdh, glyceraldehyde phosphatide hydrogenase; Mafa, v-Maf musculoaponeurotic fibrosarcoma oncogene family, protein A; Nkx6.1, NK6 homeobox transcription factor-related locus 1. 
supplementary materials given at the end of this article). We found that HFD-fed mice gained significant weight with or without STZ (Fig. 1A). Fasting blood glucose was significantly higher in the HFD and STZ-treated groups than that in the SD group (Fig. 1B). As expected, alphacell numbers increased in the HFD and STZ-treated groups (Fig. 1C and $\mathrm{H}$ ). Consistent with our previous studies (Xuan et al. 2018), the immunoreactivity of ACE2 and MAS receptors was mainly expressed in glucagon-positive alpha cells and insulin-positive beta cells, respectively
(Fig. 1D and E). In all metabolic stress models, ACE2 expression dramatically decreased (Fig. 1D and I). The beta cells of SD mice showed high levels of GAD67 and GABA immunofluorescence, which significantly declined in HFD and STZ-treated groups (Fig. 1F, G, J, K). Moreover, immunofluorescence demonstrated that the expression of GABA B receptor (GBR) in beta cells significantly decreased in the HFD+STZ group, and assessment of the mRNA levels validated changes in expression of these proteins (Supplementary Fig. 1B and C). In summary, these results

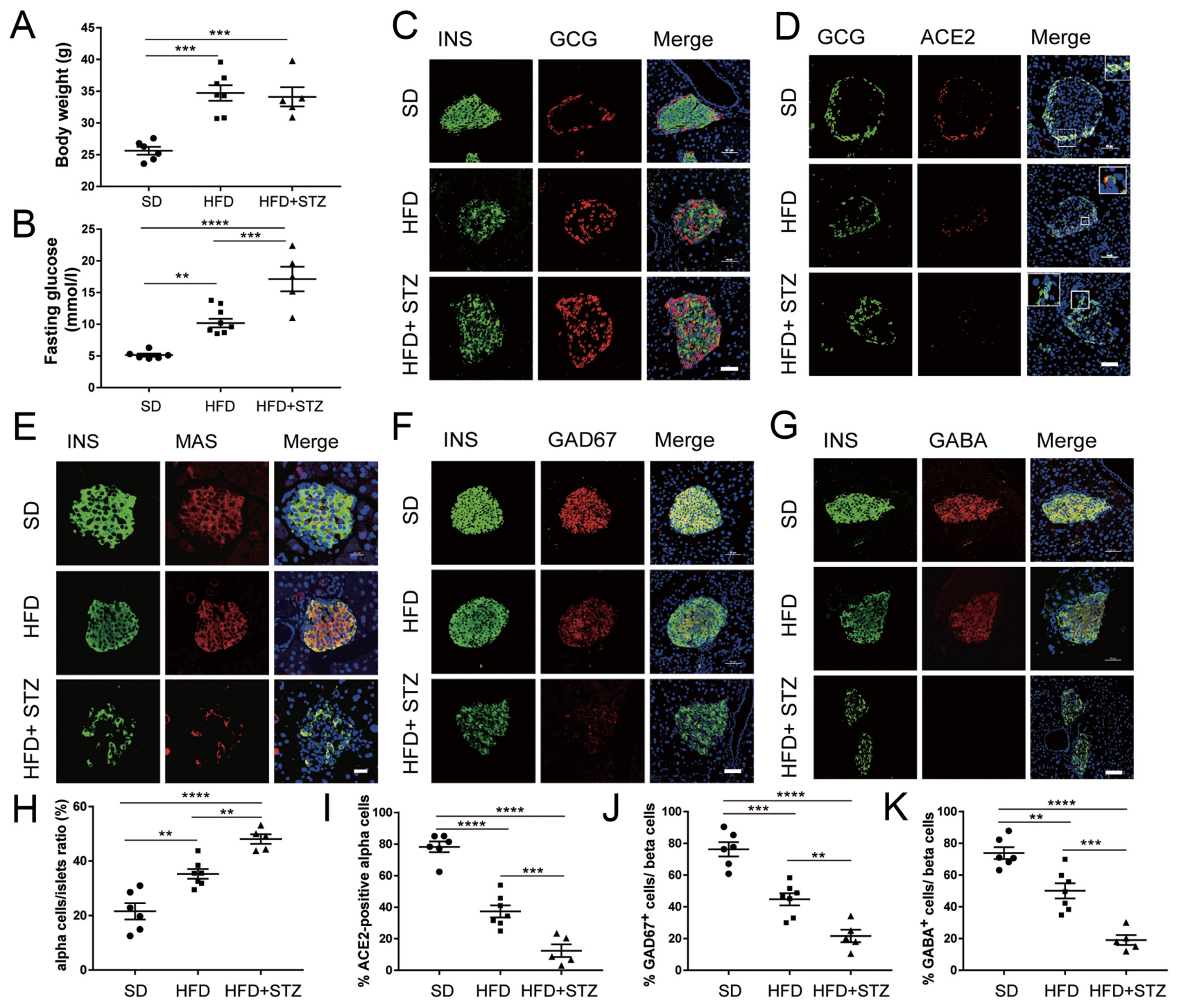

Figure 1

The expression of ACE2 and GABA signal decreases in metabolic stress models. Body weights (A) and concentrations of fasting glucose (B) of SD, HFD and HFD + STZ treated mice at the 16th week. (C) Immunostaining of insulin and glucagon in the pancreatic islets of SD, HFD and T2DM mice and assessment of the alpha cell/islets ratio (H). (D) Representative immunofluorescent images of co-staining of glucagon and ACE2 in the different groups. (E-G) Representative images of insulin and MAS (E), GAD67 (F) and GABA (G) staining. Scale bars: C, D, F, G $=50 \mu \mathrm{m}$ and E $=20 \mu \mathrm{m}$. (I-K) Ratio of double positive cells to ACE2 (I), GAD67 (J) and GABA (K). Per mouse, 20-30 islets were examined ( $n=5-7$ mice/group). Bars represent the mean \pm S.E.M., and one-way ANOVA was used for statistical analysis. ${ }^{* *} P<0.01,{ }^{* * *} P<0.001$ and ${ }^{* * * *} P<0.0001$ (SD, received standard diets; HFD, received high-fat diets; STZ, streptozotocin). 
show that both the ACE2/A1-7/MAS and GAD67/GABA signal decrease in metabolic stress models.

\section{The ACE2/A1-7/MAS axis up-regulates GABA system expression in beta cells}

To examine the effects of ACE2 on GABA expression in islets, we next established ACE2KO HFD mouse models (Supplementary Fig. 1D). At first, the plasma concentration of A1-7 was measured in the WT and ACE2KO mouse models. The A1-7 concentration was decreased in the WT HFD mice compared to the WT SD mice, while it was not detected in the ACE2KO mice with or without HFD. Nevertheless, treatment with A1-7 could increase the plasma level of A1-7 (Supplementary Fig. 1E). Surprisingly, GABA expression decreased in ACE2KO SD mice and more pronounced loss was observed following HFD intervention (Fig. 2A and C). The expression of GABA-related receptors showed no obvious changes (Supplementary Fig. 1F). The effects of ACE2 on GAD67 synthesis in beta cells were also assessed in ACE2KO HFD mice. Interestingly, consistent with the mRNA expression change in ACE2KO HFD mice, the levels of GAD67 as seen by immunofluorescence had significantly decreased, which was reversed by exogenous A1-7 administration (Fig. 2B and D). Consistent with the findings in vivo, A1-7 promoted the increase of GAD67 in MIN6 cells under PA condition, while A779 (a MAS receptor inhibitor) caused an opposing effect (Fig. 2E). To explore the role of GAD67 and GABA in the ACE2-mediated protection of beta cells, the effects of allylglycine (a specific GAD inhibitor) were investigated. As shown in Fig. $2 \mathrm{G}$ and H,

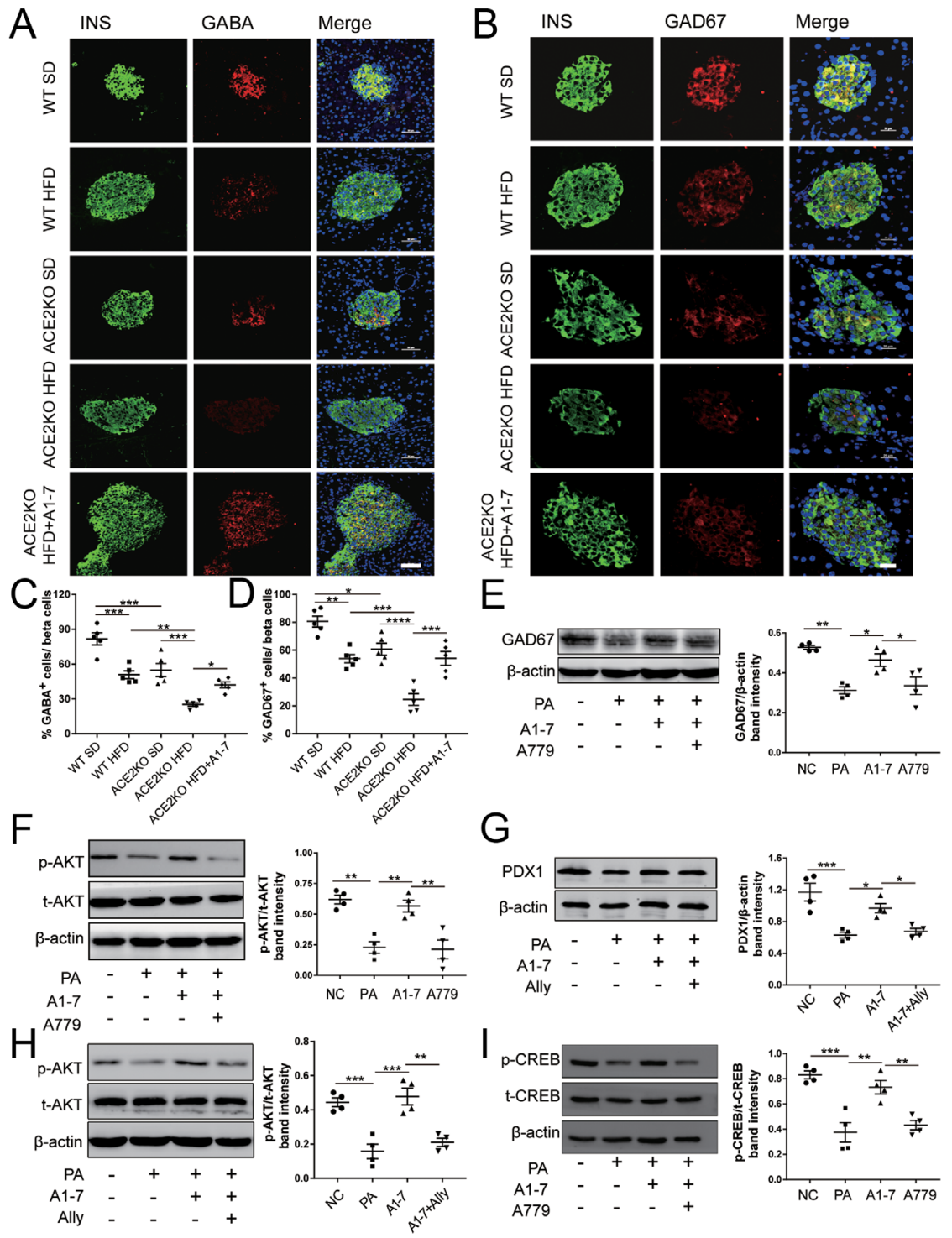

Figure 2

ACE2/A1-7/MAS axis regulates GABA system expression in beta cells. (A, C) Representative immunostaining images of insulin and GABA in the pancreatic islets and the ratio of double immunopositive cells. (B, D) IF staining of insulin and GAD67 and the ratio of GAD67

immunopositive cells. Scale bars: $A=50 \mu \mathrm{m}$ and $B=20 \mu \mathrm{m}$. (E-I) Representative immunoblots and densitometric quantification of GAD67, PDX1, $\mathrm{p}$-AKT and p-CREB proteins in MIN6 cells following exposure to PA for $48 \mathrm{~h}$ with or without A1-7 $\left(10^{-6} \mathrm{~mol} / \mathrm{L}\right)$, A779 $\left(10^{-6} \mathrm{~mol} / \mathrm{L}\right)$ or allylglycine (a GAD antagonist, $5 \mathrm{mmol} / \mathrm{L})$. One-way ANOVA was used for statistical analysis (mean \pm S.E.M., $n=4$-5/group). ${ }^{*} P<0.05,{ }^{* *} P<0.01,{ }^{* * *} P<0.001$ and ${ }^{* * * *} P<0.0001$ (NC, negative control; PA, palmitic acid). 
palmitate decreased PDX1 and p-AKT expression compared to the NC group. The incubation of MIN6 cells with A1-7 enhanced PDX1 and p-AKT levels compared to the PA group. The protective effects of A1-7 were suppressed by allylglycine (Fig. 2G and H).

It has been reported that phosphorylated CREB (p-CREB) can activate GAD67 gene transcription, which leads to GABA expression (Sánchez-Huertas \& Rico 2011, Yoo et al. 2012). As an important nuclear transcription factor, p-CREB can promote the transcription of a variety of functional genes. We found that the regulation of ACE2/A1-7/MAS axis was closely associated with the regulation of GAD67 signal in the pancreas. Therefore, we speculated that A1-7 may affect GAD67 transcription through p-CREB. To test this hypothesis, the effects of A1-7 and A779 on the expression of (p)CREB in MIN6 cells were investigated. PA decreased the expression of $\mathrm{p}-\mathrm{CREB}$, which could be increased by incubation with A1-7 (Fig. 2I). However, compared to the A1-7 group, the level of p-CREB decreased in the A779 group (Fig. 2I). These data suggest that A1-7 increases the expression of GABA through increasing GAD67 levels, which is mediated by p-CREB, and then protects beta-cell function.

\section{Up-regulation of the ACE2/A1-7/MAS axis and GABA improves glucose and lipid metabolism in HFD mice}

In order to further study their relationship in the treatment of metabolic stress, we found that the weight of the mice treated with A1-7 or/and GABA decreased compared to the HFD group, (Fig. 3A, Supplementary Fig. 2A). After feeding HFD for 16 weeks, the mice developed mild hyperglycemia $(9.83 \pm 0.17 \mathrm{mmol} / \mathrm{L})$, while FBG levels decreased in the A1-7 or GABA groups. Compared to mono-therapy groups, mice from the combined A1-7 and GABA treatment group had lower FBG values, which were comparable to the FBG of SD mice $(5.4 \pm 0.23 \mathrm{mmol} / \mathrm{L})$ (Fig. 3B). At week 12, the area under the blood glucose curve for the HFD groups significantly increased compared to the SD group (Fig. 3C, D, G, H). As shown in Fig. 3E and F, A1-7 or GABA mono-therapy partially improved glucose tolerance, which was further increased in response to combination therapy. Figure 3I and J showed that A1-7 or/and GABA treatment increased insulin sensitivity and that p-AKT signal (an important downstream effector of insulin signaling) was also enhanced in the liver and eWAT of mice treated with A1-7 or/and GABA (Supplementary Fig. 2E and F). As shown in Fig. 3K, M, N, the plasma serological levels of TG, TC and LDL significantly increased, while HDL levels declined in the HFD group compared to that in the SD group. A1-7 or/and GABA intervention led to significant reduction in the TG level compared to the HFD group, while the decline in TC and LDL levels was not statistically different compared to the HFD group (Fig. $3 \mathrm{~K}$ and $\mathrm{M}$ ). In contrast, the HDL level was significantly elevated in the $\mathrm{A}(1-7)+$ GABA group (Fig. 3N). Overall, the results indicate that the ACE2/A1-7/MAS axis and GABA improve glucose and lipid metabolism under metabolic stress.

\section{A1-7 and GABA treatment remodels alpha and beta cells in the islets}

To explore the mechanism of improved glucose tolerance after combination therapy, we next assessed the number of alpha and beta cells in all five groups (Fig. 3A). The treatment of A1-7 or/and GABA recovered islet structures and decreased fat deposition compared to the HFD group (Fig. 4A). Unlike the islet in HFD mice, H\&E and immunofluorescence analysis showed normal alpha- and beta-cell distribution of the islet in A1-7 and GABAtreated mice (Fig. 4A).

Measurement of alpha-cell mass in the HFD group revealed a 44\% increase compared to the SD mice (Fig. 4B). As shown in Fig. 3B, C, D, A1-7 or GABA mono-therapy partially increased beta/alpha cell mass and insulin content, which further increased upon combination therapy. RT-PCR analysis showed that the expression of $P d x 1, N k x 6.1, M a f a$, and insulin declined in HFD islets, while it had an overall increase in the $\mathrm{A}(1-7)+\mathrm{GABA}$ group, most notably for PDX1 (Fig. 4E) Although the fasting insulin level in the $A(1-7)+G A B A$ group decreased compared to HFD group, insulin release increased significantly after $30 \mathrm{~min}$ of glucose stimulation (Fig. 4F). Glucagon-like peptide-1 (GLP-1), a marker of immature alpha cells (Habener \& Stanojevic 2013), showed significant increase in the HFD group to protect beta cells. A1-7 and GABA improved islet metabolism and led to a decrease in GLP-1 expression, allowing alpha cells to restore glucagon expression (Fig. 4G and H). Taken together, the aforementioned data suggest that A1-7 and GABA treatment remodels alpha and beta cells in metabolic stress model.

\section{A1-7 and GABA treatment produces additive effects on beta-cell dedifferentiation}

No difference in the size of beta cells was observed in Fig. 4A, indicating that the increased beta-cell mass observed in A1-7 or GABA groups was unlikely due to 

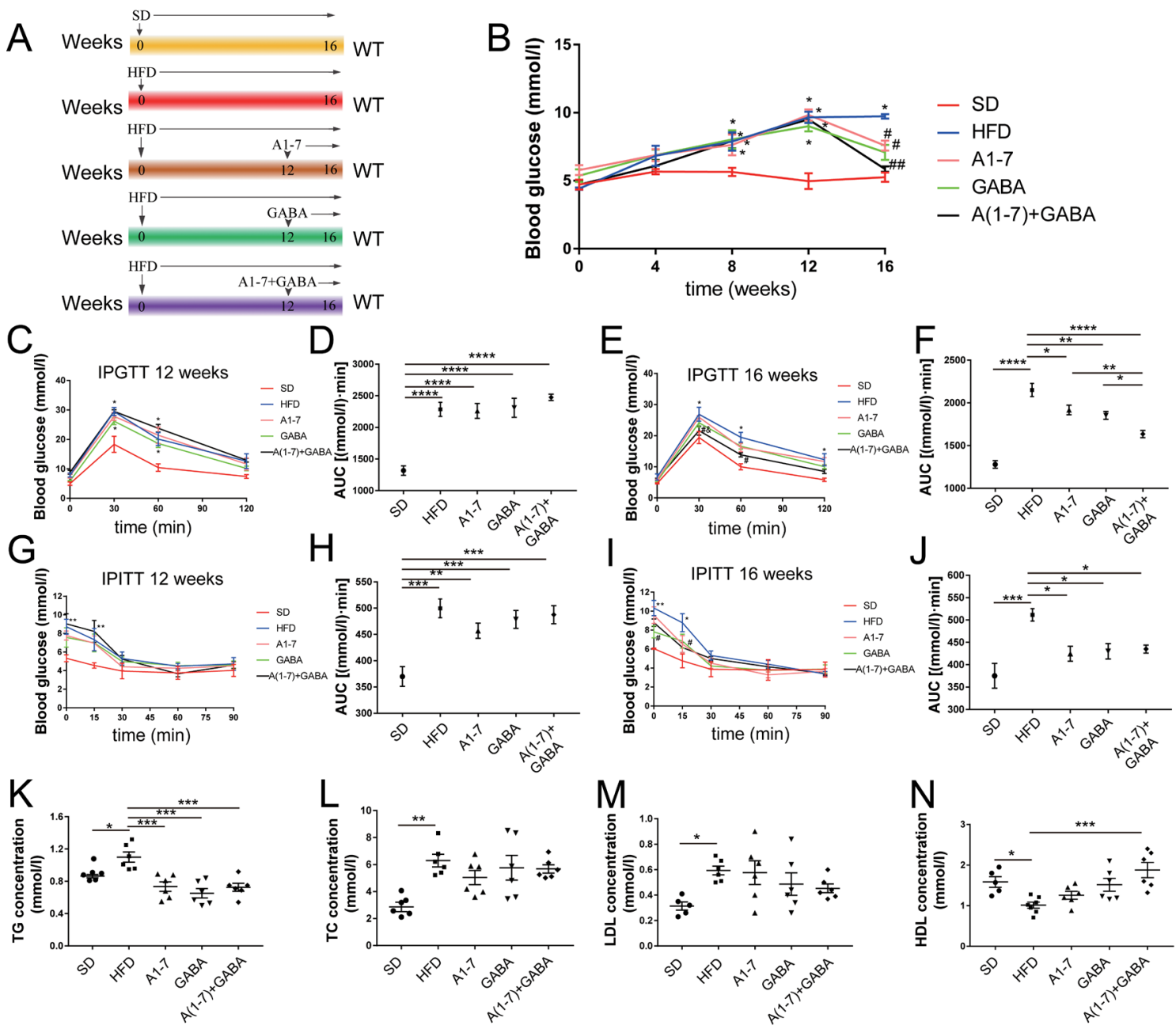

\section{Figure 3}

A1-7 and GABA improve glucose and lipid metabolism in HFD-fed mice. (A) Experimental schedule. (B) Fasting blood glucose levels in the five groups. (C-F) IPGTTs performed at 12 (C) and 16 weeks (E) to evaluate blood glucose levels. AUC of the IPGTT (D, F). (G-J) IPITTs performed at 12 (G) and 16 weeks (I) in different groups. AUC of IPITT (H, J). (K-N) Effects of A1-7 or/and GABA on the serum levels of TG (K), TC (L), LDL (M) and HDL (N) levels in C57BL/6J mice. Values are the mean \pm S.E.M. of 5-8 mice/group. One-way or two-way ANOVA used for statistical analysis. ${ }^{*} P<0.05$ and ${ }^{* *} P<0.01$ vs SD group; $\# P<0.05$ and $\# P<0.01$ vs HFD group; \& $P<0.05$ vs $A 1-7$ treated group for $(B, C, E, G, I) .{ }^{*} P<0.05,{ }^{* *} P<0.01,{ }^{* * *} P<0.001$ and ${ }^{* * * *} P<0.0001$ for $(D, F, H, J-N)$. (A1-7, HFD mice received angiotensin 1-7; GABA, HFD mice received gamma-aminobutyric acid; A(1-7) + GABA, HFD mice received A1-7 plus GABA). A full colour version of this figure is available at https://doi.org/10.1530/JOE-19-0471.

changes in beta-cell size, so beta-cell proliferation and apoptosis were assessed in the following. Despite the apparent increase in beta-cell numbers with A1-7 or/and GABA intervention, there were no corresponding mitotic Ki67 positive beta-cells (Supplementary Fig. 2B and $\mathrm{C}$ ), which might contradict with previous reports suggesting that GABA promotes beta-cell proliferation in T1DM (Liu et al. 2017). Evaluation of apoptosis by TUNEL staining revealed no difference between these groups (Supplementary Fig. 2D). Using genetic lineage technique, previous studies and our research had shown that the low beta-cell numbers during metabolic stress was not due to beta-cell apoptosis, but dedifferentiation
(Talchai et al. 2012, Wang et al. 2014, Bensellam et al. 2018, Xuan et al. 2018). As shown in Fig. 5, GABA mono-therapy decreased the numbers of octamer-binding transcription factor-4 (OCT4) and neurogenin 3 (NGN3) positive beta cells to $37.5 \%$ and $47.3 \%$, respectively. Furthermore, $A(1-7)+G A B A$ treatment produced synergistic effects on the decrease of progenitor cells in the islets (Fig. 5A, B, C, D). Up-regulating the ACE2/A1-7/MAS axis and GABA also decreased the expression of Ngn3 and Oct4 at the mRNA and protein level (Fig. 5E and F).

To further investigate the improvement of dedifferentiated beta-cell function after the A1-7 or/and GABA treatment, we co-stained insulin and forkhead 


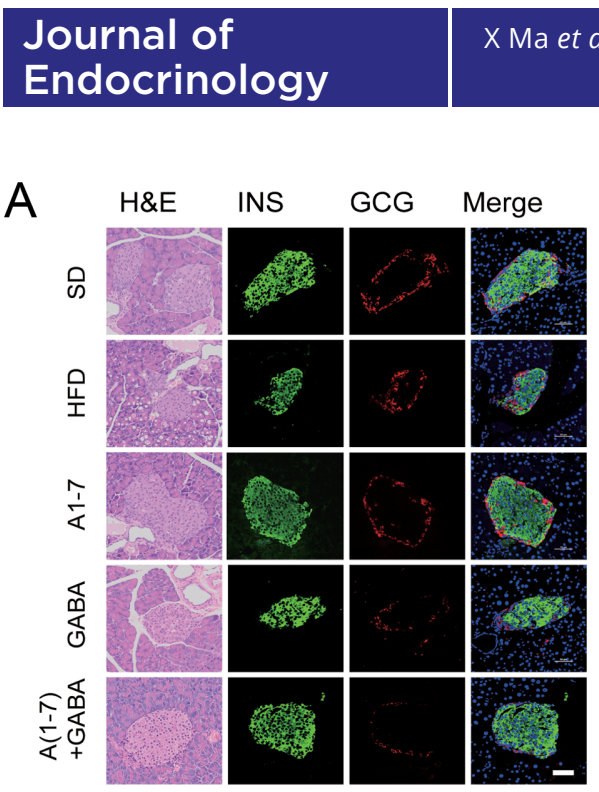

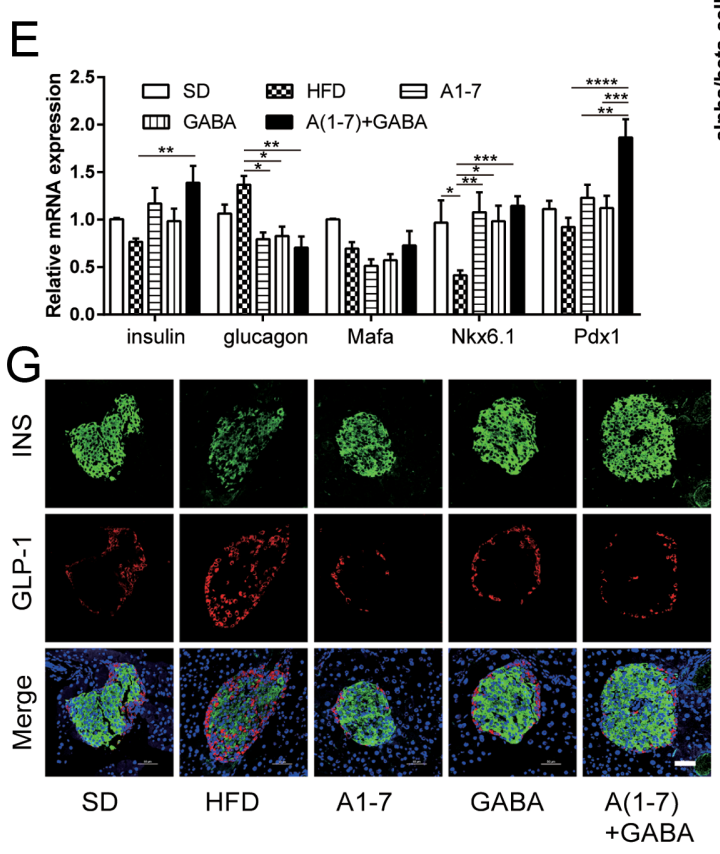

$\mathrm{B}$ 宊

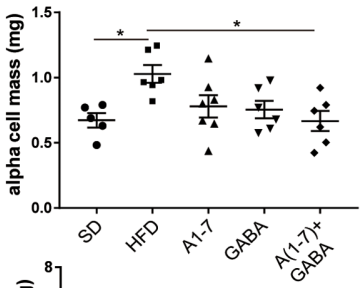

C

D
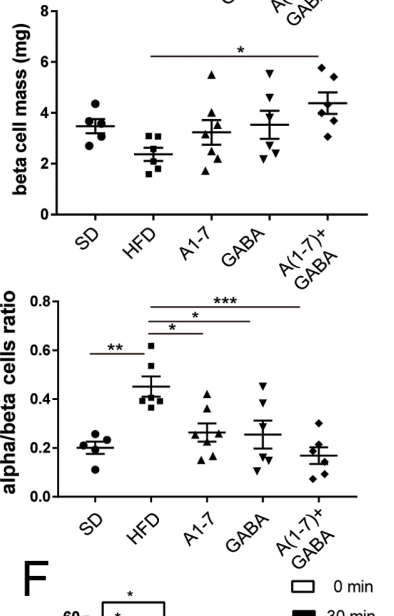

Figure 4

Up-regulation of A1-7 and GABA remodels the balance of alpha and beta cells in islets. (A) Representative hematoxylin-eosin (H\&E) or double-stained images of insulin and glucagon in pancreatic islets. (B) Pancreatic alpha cell mass. (C) Pancreatic beta cell mass. (D) Alpha/beta ratio in islets. (E) Real-time PCR analysis of insulin and its transcription factors and glucagon in the mouse pancreases. (F) Plasma insulin levels at the indicated times during IPGTT assays. (G)

Representative immunofluorescence images of insulin positive (green) and GLP-1 positive (red) cells. (H) Ratio of GLP-1 positive cells in islets. Scale bars $=50 \mu \mathrm{m}$. Unpaired two-tailed Student's $t$-test, one-way or two-way ANOVA was used for statistical analysis (mean \pm S.E.M., $n=5-8$ mice/ group). ${ }^{*} P<0.05,{ }^{* *} P<0.01,{ }^{* * *} P<0.001$ and ${ }^{* * * *} P<0.0001$ box O1 (FOXO1), key markers of mature beta cells. In contrast to the OCT4 data, the FOXO1+/insulin+ double positive cell counts increased in A1-7 (51.94 $\pm 2.87 \%)$ and GABA $(57.18 \pm 3.03 \%)$ treated groups compared to HFD mice $(38.63 \pm 4.23 \%)$ and combined therapy led to synergistic effects $(64.08 \pm 3.52 \%)$ (Fig. $6 \mathrm{~A}$ and C). Additionally, the increased expression of prohormone convertase 1/3 (PC1/3, an enzyme involved in insulin synthesis) in beta cells suggested a functional recovery of beta cells in the A1-7 or/and GABA groups (Fig. 6B and D). Consistent with previous studies (Huang et al. 2015), there were some PC1/3-positive cells in extracellular betacell compartments, explaining the increase in GLP-1 (Figs $4 \mathrm{G}$ and 6B). Endothelial cells in islets were one of the important components of microcirculation. There was a significant decrease in VEGF expression in HFD mice, with simultaneous decrease in endothelial nitric oxide synthase (eNOS) expression, suggesting that the function of endothelial cells in islet was impaired during metabolic stress (Fig. 6E, F, G). The grayscale values of eNOS in both GABA and $A(1-7)+$ GABA groups increased significantly than those of the HFD group (Fig. 6G). These data suggest that combined A1-7 and GABA treatment provides excellent long-term protection against beta-cell dysfunction in response to metabolic stress.

\section{The combination of A1-7 and GABA restores beta-cell function under lipid toxicity}

In order to eliminate environmental influence in the pancreas, the experiments were performed in vitro to directly investigate the effects of $\mathrm{A} 1-7$ or/and GABA on 


\begin{tabular}{l|l|l|l|l|}
$\begin{array}{l}\text { Journal of } \\
\text { Endocrinology }\end{array}$ & $\begin{array}{l}\text { Relationship between ACE2 } \text { al. } \\
\text { and GABA in islet }\end{array}$ & $246: 3$ & 232 \\
\hline
\end{tabular}
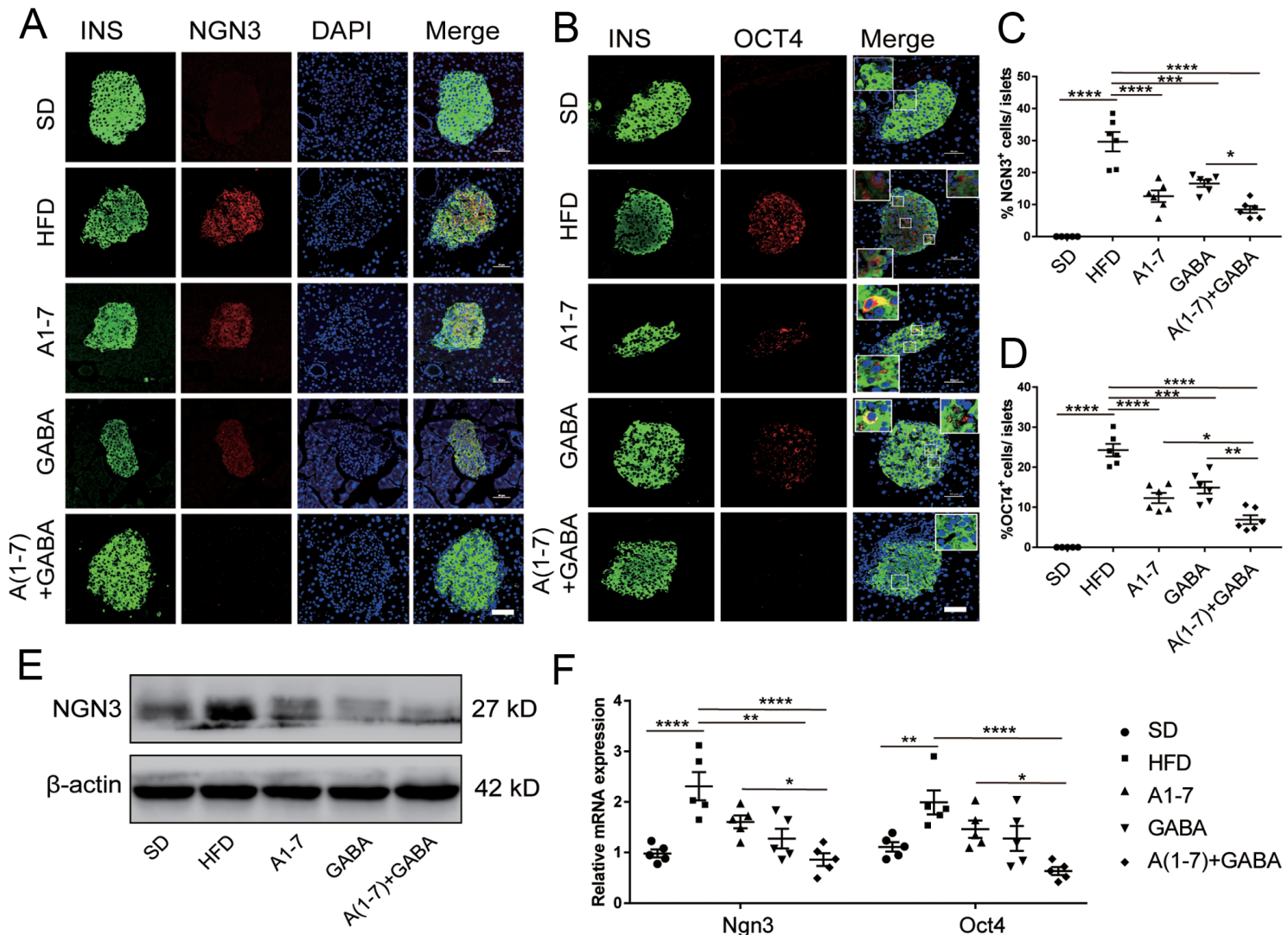

$\mathrm{F}$

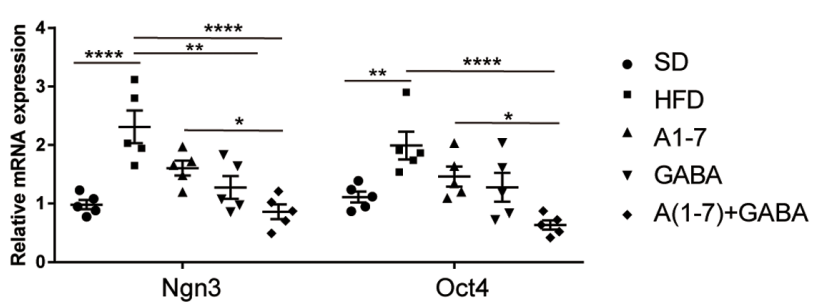

Figure 5

Upregulation of A1-7 and GABA produces additive effects on beta-cell dedifferentiation. (A, B) Representative images of cells double-stained for insulin and NGN3 (A) or OCT4 (B). Scale bars $=50 \mu \mathrm{m}$. (C, D) Proportion of OCT4-positive and NGN3-positive dedifferentiated cells. (E) Western blot of NGN3 expression in the pancreas. (F) Real-time PCR analysis of Ngn3 and Oct4 in the pancreas. One-way or two-way ANOVA was used for statistical analysis (mean \pm S.E.M., $n=5-6$ mice/group). ${ }^{*} P<0.05,{ }^{* *} P<0.01,{ }^{* * *} P<0.001$ and ${ }^{* * * *} P<0.0001$.

beta-cell function. As shown in Fig. 7A and B, insulin levels and the expression of insulin-related transcription factors decreased exposure to PA, while they were improved by incubating with A1-7 or GABA. Similar to the primary islets, the $A(1-7)+G A B A$ group showed normal levels of insulin secretion in MIN6 cells under PA condition (Fig. 7C). The mRNA levels of insulin, Pdx1, Mafa and Nkx6.1 were also up-regulated in MIN6 cells following $A(1-7)+$ GABA treatment (Fig. 7D). AKT was activated by $A 1-7$ and GABA, indicating insulin sensitivity was enhanced (Fig. 7E). As a result, the combination of A1-7 and GABA restores beta-cell function under lipid toxicity in vitro and activates AKT-mediated insulin signaling.

\section{Discussion}

Previous studies have shown that the ACE2/A1-7/MAS axis and GABA system express in the pancreas, both playing important roles in islet function. However, the relationship between the two systems in pancreas is still unclear. In this study, we found that the expression of ACE2 and GABA signal both decreased in islets in metabolic stress models of obesity and T2DM. Next, we assessed the expression of GAD67 and GABA in islets and found their levels to be down-regulated in ACE2KO mice especially fed with HFD, which was reversed by A1-7 treatment. Consistent with these data in vivo, A1-7 enhanced GAD67 level in MIN6 cells under PA condition. The effects of A1-7 on the p-AKT and PDX1 in MIN6 cells could also be intercepted by allylglycine. Moreover, up-regulation of the ACE2/A1-7/MAS axis and GABA individually or in combination could delay the development of obesityinduced diabetes and produce synergistic effects on betacell differentiation and maturation. Taken together, these data suggest that the ACE2/A1-7/MAS axis attenuates betacell dysfunction during metabolic stress by promoting GABA signal.

To date, several studies have focused on beta-cell function in T2DM, but the role of alpha cells in disease 


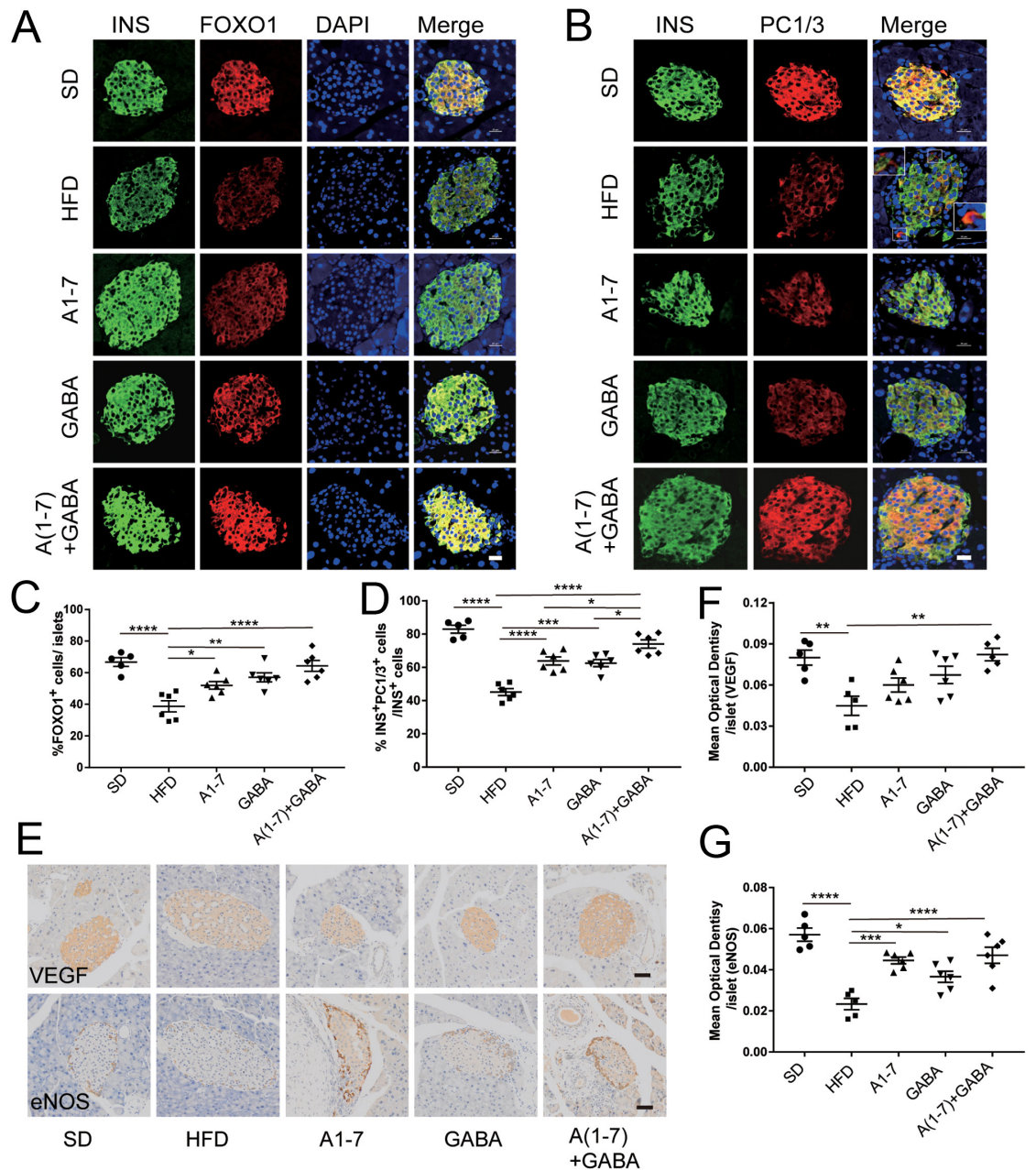

\section{Figure 6}

A1-7 and GABA promotes the maturation of beta cells. (A, B) Representative images of $\mathrm{FOXO} 1^{+}$beta cells (A) and $\mathrm{PC} 1 / 3^{+}$cells (B) in pancreatic islets. $(C, D)$ Chart summarizing the percentage of total FOXO1+ cells in the islets (C) and insulin ${ }^{+} \mathrm{PC} 1 / 3^{+}$ cells in insulin positive cells (D). (E-G) Immunohistochemistry (IHC) staining of VEGF and eNOS in mouse pancreas. Histograms represent the mean intensity of VEGF and eNOS in the islets. Scale bars: $A, B=20 \mu \mathrm{m}$ and $E=50 \mu \mathrm{m}$. One-way ANOVA was used for statistical analysis (mean \pm s.E.M., $n=5-6$ mice/group). ${ }^{*} P<0.05$, ${ }^{* *} P<0.01,{ }^{* * *} P<0.001$ and ${ }^{* * * *} P<0.0001$ (VEGF, vascular endothelial growth factor; eNOS, endothelial nitric oxide synthase).

pathogenesis is less well understood. In recent years, our knowledge of alpha cells has improved and their critical role in islet function has been recognized (Gromada et al. 2018). Consistent with recent studies, we found ACE2 primarily expressed in alpha cells (Brar et al. 2017, Xuan et al. 2018), while its MAS receptors and GABA distributed in beta cells in the islet. Previous studies suggest that ACE2 protects beta cells mainly via catalytic product A1-7 that acts on MAS receptors in endothelial cells and plays a role in dilating blood vessels and improving islet microcirculation. However, ACE2 is mainly studied as a vascular regulator rather than a hypoglycemic factor, although ACE2 is highly expressed in alpha cells. Previous studies have focused on exploring the role of GABA in T1DM (Feng et al. 2017, Prud'Homme et al. 2017); however, GABA is less well studied in beta cells of T2DM and obesity models. The alpha and beta cells are adjacent and their precise paracrine regulation is achieved through intercellular paracrine signaling. In our study, we found that A1-7 could regulate the expression of GABA in beta cells and produce superior therapeutic effects in prediabetes condition and delay the development of obesityinduced diabetes.

Under certain conditions, alpha cells can be transdifferentiated into beta cells, which become a new source of beta-cell regeneration (Lu et al. 2016, Gromada et al. 2018, Efrat 2019). Consistent with the role of A1-7 or GABA in promoting the survival and replication of mouse beta cells (Bindom et al. 2010, Soltani et al. 2011), we discovered that A1-7 and GABA combination treatment further increased beta-cell mass, correlating with the decreased precursor marker positive cells and increased functional FoxO1 and PC1/3 positive beta-cell numbers (Figs 5 and 6). By beta-cell genetic lineage tracking technology, our previous study demonstrated that HFDinduced metabolic stress mice undergo dedifferentiation as mechanism of self-protection (Xuan et al. 2018). Notably, the combined treatment increased beta-cell mass via improved protection against beta-cell dedifferentiation. Therefore, we hypothesized that the combined effects of 


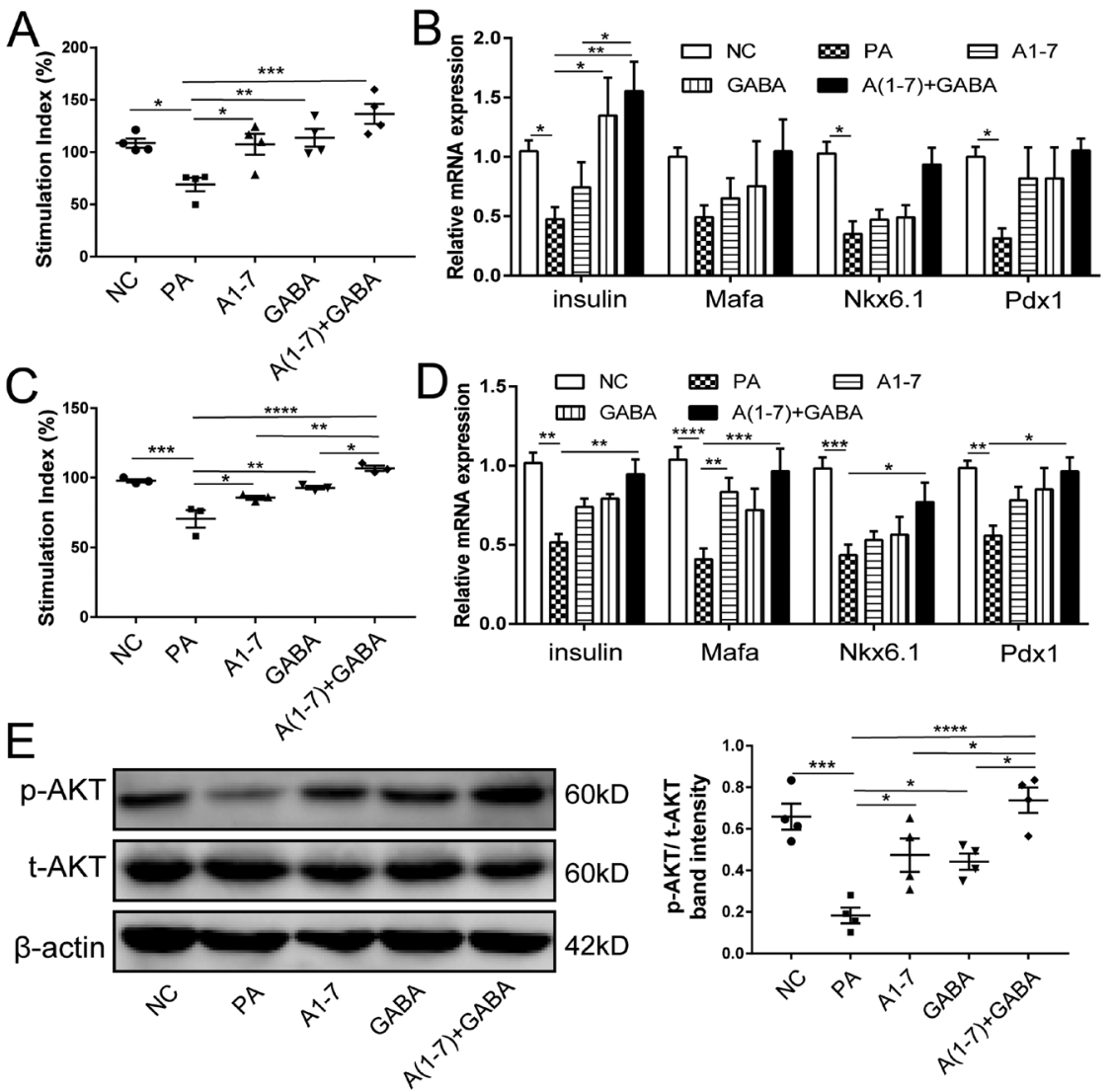

\begin{abstract}
Figure 7
Effects of A1-7 and GABA on insulin secretion of beta cells in vitro. (A, C) Glucose-stimulated insulin secretion was analyzed in primary islets (A) and MIN6 cells $(C)$ incubated in media containing $2.8 \mathrm{mmol} / \mathrm{L}$ (basal) or $16.7 \mathrm{mmol} / \mathrm{L}$ (stimulated) glucose for $1 \mathrm{~h}$ at $37^{\circ} \mathrm{C}$. (B, D) Quantitative real-time PCR was used to measure the level of insulin and other maturation makers in primary islets (B) and MIN6 cells (D). (E) Western blot and quantitative analysis of $\mathrm{p}-\mathrm{AKT}$ and total AKT in MIN6 cells treated with the indicated interventions. Data are mean \pm s.E.M. $(n=3-4)$. One-way or two-way ANOVA was used for statistical analysis. ${ }^{*} P<0.05,{ }^{* *} P<0.01,{ }^{* * *} P<0.001$ and ${ }^{* * * *} P<0.0001$.
\end{abstract}

A1-7 and GABA were due to their effects on beta cells. In addition to increasing beta-cell mass, treatment with A1-7, GABA or combination treatment reduced alpha-cell counts and GLP-1 levels, which represented immature alpha cells (Habener \& Stanojevic 2013, Huang et al. 2015). The reduced alpha cells following GABA treatment in HFD mouse model were in agreement with previous T1DM studies (Soltani et al. 2011). Recent studies have shown that GABA or the antimalarial drug, artemether, drives alpha cells toward beta-cell transdifferentiation (Ben-Othman et al. 2017, Li et al. 2017, Weir \& BonnerWeir 2017) and that these drugs stimulate the production of new beta-cell-like cells to reverse diabetes in mice. In contrast to studies identifying GABA as a potential inducer of alpha to beta-cell transdifferentiation for diabetic therapy, using alpha-cell-specific genetic lineage tracking technology, Ackermann (Ackermann et al. 2018) and van der Meulen (van der Meulen et al. 2018) found no alphato-beta-cell transdifferentiation in mice treated with artesunate or GABA for a sustained period either in vivo or in vitro. We assessed both alpha and beta-cell biomarkers after a 4-week GABA or combined treatment and observed no glucagon/GLP-1 or insulin double positive alpha cells, which was consistent with the results from Ackermann (Ackermann et al. 2018). Therefore, we suggest that there is no apparent transdifferentiation phenomenon between alpha and beta cells because the beta-cell loss is limited in HFD-induced obesity models (prediabetes models).

In the present study, we found that up-regulation of the ACE2/A1-7/MAS axis promoted the expression of GAD67 and GABA, suggesting that functional ACE2/ A1-7/MAS signal in islets was closely related to the GABA signaling system. In addition, we discovered that the regulatory balance was restored between alpha/beta cells under metabolic stress through simultaneous restoration of the ACE2/A1-7/MAS axis and GABA signaling system, remodeling islet function and preventing diabetes. Therefore, we infer that ACE2 of alpha cells is closely related to GABA expressed by beta cells, which together constitutes a novel and important paracrine regulatory network system. In this network system, ACE2 is secreted by alpha cells and converts angiotensin II into A1-7, which activates the MAS receptors in beta cells and promotes the production of GABA. Then, GABA promotes beta-cell function and insulin release through autocrine secretion, while it inhibits glucagon release through 
paracrine signaling to maintain islet balance. This has an important implication for beta-cell biology and represents a potential treatment strategy for diabetes.

In conclusion, our data suggest that the ACE2/A1-7/ MAS axis is closely related to GABA signaling system in the islet. The ACE2/A1-7/MAS axis promotes the expression of GAD67/GABA signal through phosphorylation of CREB in beta cells, whereby A1-7 and GABA play an important role in pre-diabetic condition, causing a delay in development of diabetes and attenuating beta-cell dedifferentiation. In the islet, the ACE2/A1-7/MAS axis and GABA system may form a novel paracrine signaling system between alpha and beta cells. These findings may provide a new theoretical basis for the paracrine regulation mechanisms of islet function and allow the exploration of new intervention targets for the prevention and treatment of T2DM.

\section{Supplementary materials}

This is linked to the online version of the paper at https://doi.org/10.1530/ JOE-19-0471.

\section{Declaration of interest}

The authors declare that there is no conflict of interest that could be perceived as prejudicing the impartiality of the research reported.

\section{Funding}

This work was supported by the National Natural Science Foundation of China (grant numbers 81570700,81974104 ).

\section{Author contributions}

Ma XY, Gao F and Xuan XP were involved in designing this study and performed in vivo experiments. Chen Q, Yang FY and Deng HJ performed in vitro experiments. $\mathrm{Ma} X \mathrm{X}, \mathrm{Chen} \mathrm{Q}$ and Wang $\mathrm{Y}$ performed acquisition of data. Ma XY, Xuan XP and Wang $Y$ performed statistical analysis and interpretation of data. Ma XY wrote the manuscript. Yuan $L$ performed critical revision of the manuscript and approved the final version for publication.

\section{Acknowledgements}

The authors gratefully acknowledge Shunchang Zhou and Huanhuan Yan for the helpful discussion and suggestions and Pei Pang, Duo Li for the assistance with equipment maintenance and experimental guidance. The authors also sincerely thank all investigators from Union Hospital, Tongji Medical College, Huazhong University of Science and Technology, Wuhan, China.

\section{References}

Ackermann AM, Moss NG \& Kaestner KH 2018 GABA and aartesunate do not induce pancreatic $\alpha$-to- $\beta$ cell ttransdifferentiation in vivo. Cell Metabolism 28 787-792.e3. (https://doi.org/10.1016/j. cmet.2018.07.002)
Ben-Othman N, Vieira A, Courtney M, Record F, Gjernes E, Avolio F, Hadzic B, Druelle N, Napolitano T, Navarro-Sanz S, et al. 2017 Longterm GABA administration induces alpha cell-mediated beta-like cell neogenesis. Cell 168 73-85.e11. (https://doi.org/10.1016/j. cell.2016.11.002)

Bensellam M, Jonas JC \& Laybutt DR 2018 Mechanisms of beta-cell dedifferentiation in diabetes: recent findings and future research directions. Journal of Endocrinology 236 R109-R143. (https://doi. org/10.1530/JOE-17-0516)

Bindom SM, Hans CP, Xia H, Boulares AH \& Lazartigues E 2010 Angiotensin I-converting enzyme type 2 (ACE2) gene therapy improves glycemic control in diabetic mice. Diabetes 59 2540-2548. (https://doi.org/10.2337/db09-0782)

Brar GS, Barrow BM, Watson M, Griesbach R, Choung E, Welch A, Ruzsicska B, Raleigh DP \& Zraika S 2017 Neprilysin is required for angiotensin-(1-7)'s ability to enhance insulin secretion via its proteolytic activity to generate angiotensin-(1-2). Diabetes 66 2201-2212. (https://doi.org/10.2337/db16-1318)

Cheng J, Deng R, Zhang P, Wu C, Wu K, Shi L, Liu X, Bai J, Deng M, Shuai X, et al. 2015 miR-219-5p plays a tumor suppressive role in colon cancer by targeting oncogene Sall4. Oncology Reports 34 1923-1932. (https://doi.org/10.3892/or.2015.4168)

Efrat S 2019 Concise review: beta-cell dedifferentiation in type 2 diabetes. Stem Cells 9999 1267-1272. (https://doi.org/10.1002/ stem.3059)

Feng AL, Xiang YY, Gui L, Kaltsidis G, Feng Q \& Lu WY 2017 Paracrine GABA and insulin regulate pancreatic alpha cell proliferation in a mouse model of type 1 diabetes. Diabetologia 60 1033-1042. (https:// doi.org/10.1007/s00125-017-4239-X)

Feng MM, Xiang YY, Wang S \& Lu WY 2013 An autocrine gammaaminobutyric acid signaling system exists in pancreatic beta-cell progenitors of fetal and postnatal mice. International Journal of Physiology, Pathophysiology \& Pharmacology 5 91-101.

Gromada J, Chabosseau P \& Rutter GA 2018 The alpha-cell in diabetes mellitus. Nature Reviews: Endocrinology 14 694-704. (https://doi. org/10.1038/s41574-018-0097-y)

Habener JF \& Stanojevic V 2013 Alpha cells come of age. Trends in Endocrinology \& Metabolism 24 153-163. (https://doi.org/10.1016/j. tem.2012.10.009)

Hu C \& Jia W 2018 Diabetes in China: epidemiology and genetic risk factors and their clinical utility in personalized medication. Diabetes 67 3-11. (https://doi.org/10.2337/dbi17-0013)

Huang C, Yuan L \& Cao S 2015 Endogenous GLP-1 as a key self-defense molecule against lipotoxicity in pancreatic islets. International Journal of Molecular Medicine 36 173-185. (https://doi.org/10.3892/ ijmm.2015.2207)

Kehlenbrink S, Smith J, Ansbro É, Fuhr DC, Cheung A, Ratnayake R, Boulle P, Jobanputra K, Perel P \& Roberts B 2019 The burden of diabetes and use of diabetes care in humanitarian crises in lowincome and middle-income countries. Lancet Diabetes \& Endocrinology 8 1-10. (https://doi.org/10.1016/S2213-8587(19)30082-8)

Legat L, Smolders I \& Dupont AG 2018 GABAergic signaling mediates central cardiovascular angiotensin II type 2 receptor effects. Trends in Endocrinology \& Metabolism 29 605-606. (https://doi.org/10.1016/j. tem.2018.04.005)

Li J, Casteels T, Frogne T, Ingvorsen C, Honoré C, Courtney M, Huber KVM, Schmitner N, Kimmel RA, Romanov RA, et al. 2017 Artemisinins target GABA A receptor signaling and impair $\alpha$ cell identity. Cell 168 86-100.e15. (https://doi.org/10.1016/j. cell.2016.11.010)

Liu J, Yang K, Yang J, Xiao W, Le Y, Yu F, Gu L, Lang S, Tian Q, Jin T, et al. 2019 Liver-derived fibroblast growth factor 21 mediates effects of glucagon-like peptide-1 in attenuating hepatic glucose output. EBioMedicine 41 73-84. (https://doi.org/10.1016/j.ebiom.2019.02.037)

Liu W, Son DO, Lau HK, Zhou Y, Prud'homme GJ, Jin T \& Wang Q 2017 Combined oral administration of GABA and DPP-4 inhibitor 
prevents beta cell damage and promotes beta cell regeneration in mice. Frontiers in Pharmacology 8 362-371. (https://doi.org/10.3389/ fphar.2017.00362)

Liu Y, Deng J \& Fan D 2019 Ginsenoside Rk3 ameliorates high-fat-diet/ streptozocin induced type 2 diabetes mellitus in mice via the AMPK/ Akt signaling pathway. Food \& Function 10 2538-2551. (https://doi. org/10.1039/c9fo00095j)

Lu J, Liu KC, Schulz N, Karampelias C, Charbord J, Hilding A, Rautio L, Bertolino P, Ostenson CG, Brismar K, et al. 2016 IGFBP1 increases beta-cell regeneration by promoting alpha- to beta-cell transdifferentiation. EMBO Journal 35 2026-2044. (https://doi. org/10.15252/embj.201592903)

Mita Y, Nakayama K, Inari S, Nishito Y, Yoshioka Y, Sakai N, Sotani K, Nagamura T, Kuzuhara Y, Inagaki K, et al. 2017 Selenoprotein P-neutralizing antibodies improve insulin secretion and glucose sensitivity in type 2 diabetes mouse models. Nature Communications 8 1568-1584. (https://doi.org/10.1038/s41467-017-01863-z)

Prud'Homme GJ, Glinka Y, Kurt M, Liu W \& Wang Q 2017 The anti-aging protein Klotho is induced by GABA therapy and exerts protective and stimulatory effects on pancreatic beta cells. Biochemical and Biophysical Research Communications 493 1542-1547. (https://doi. org/10.1016/j.bbrc.2017.10.029)

Purwana I, Zheng J, Li X, Deurloo M, Son DO, Zhang Z, Liang C, Shen E, Tadkase A, Feng ZP, et al. 2014 GABA promotes human beta-cell proliferation and modulates glucose homeostasis. Diabetes 63 4197-4205. (https://doi.org/10.2337/db14-0153)

Ramracheya RD, McCulloch LJ, Clark A, Wiggins D, Johannessen H, Olsen MK, Cai X, Zhao CM, Chen D \& Rorsman P 2016 PYYdependent restoration of impaired insulin and glucagon secretion in type 2 diabetes following roux-en-Y gastric bypass surgery. Cell Reports 15 944-950. (https://doi.org/10.1016/j.celrep.2016.03.091)

Sánchez-Huertas C \& Rico B 2011 CREB-dependent regulation of GAD65 transcription by BDNF/TrkB in cortical interneurons. Cerebral Cortex 21 777-788. (https://doi.org/10.1093/cercor/bhq150)

Sharp J \& Vermette P 2017 An in-situ glucose-stimulated insulin secretion assay under perfusion bioreactor conditions. Biotechnology Progress 33 454-462. (https://doi.org/10.1002/btpr.2407)

Shi TT, Yang FY, Liu C, Cao X, Lu J, Zhang XL, Yuan MX, Chen C \& Yang JK 2018 Angiotensin-converting enzyme 2 regulates mitochondrial function in pancreatic $\beta$-cells. Biochemical and Biophysical Research Communications 495 860-866. (https://doi. org/10.1016/j.bbrc.2017.11.055)

Soltani N, Qiu H, Aleksic M, Glinka Y, Zhao F, Liu R, Li Y, Zhang N, Chakrabarti R, Ng T, et al. 2011 GABA exerts protective and regenerative effects on islet beta cells and reverses diabetes. PNAS $\mathbf{1 0 8}$ 11692-11697. (https://doi.org/10.1073/pnas.1102715108)

Talchai C, Xuan S, Lin HV, Sussel L \& Accili D 2012 Pancreatic beta cell dedifferentiation as a mechanism of diabetic beta cell failure. Cell $\mathbf{1 5 0}$ 1223-1234. (https://doi.org/10.1016/j.cell.2012.07.029)

Taneera J, Jin Z, Jin Y, Muhammed SJ, Zhang E, Lang S, Salehi A, Korsgren O, Renström E, Groop L, et al. $2012 \gamma$-Aminobutyric acid (GABA) signalling in human pancreatic islets is altered in type 2 diabetes. Diabetologia 55 1985-1994. (https://doi.org/10.1007/s00125012-2548-7)

van der Meulen T, Lee S, Noordeloos E, Donaldson CJ, Adams MW, Noguchi GM, Mawla AM \& Huising MO 2018 Artemether does not turn $\alpha$ cells into $\beta$ cells. Cell Metabolism 27 218-225.e4. (https://doi. org/10.1016/j.cmet.2017.10.002)
Wan Y, Wang Q \& Prud'homme GJ 2015 GABAergic system in the endocrine pancreas: a new target for diabetes treatment. Diabetes, Metabolic Syndrome and Obesity: Targets and Therapy 8 79-87. (https:// doi.org/10.2147/DMSO.S50642)

Wang C, Mao R, Van De Casteele M, Pipeleers D \& Ling Z 2007 Glucagonlike peptide- 1 stimulates GABA formation by pancreatic $\beta$-cells at the level of glutamate decarboxylase. American Journal of Physiology: Endocrinology and Metabolism 292 E1201-E1206. (https://doi. org/10.1152/ajpendo.00459.2006)

Wang L, de Kloet AD, Pati D, Hiller H, Smith JA, Pioquinto DJ, Ludin JA, Oh SP, Katovich MJ, Frazier CJ, et al. 2016 Increasing brain angiotensin converting enzyme 2 activity decreases anxietylike behavior in male mice by activating central Mas receptors. Neuropharmacology 105 114-123. (https://doi.org/10.1016/j. neuropharm.2015.12.026)

Wang Q, Ren L, Wan Y \& Prud'Homme GJ 2019 GABAergic regulation of pancreatic islet cells: physiology and antidiabetic effects. Journal of Cellular Physiology [epub]. (https://doi.org/10.1002/jcp.28214)

Wang W, Wu RD, Chen P, Xu XJ, Shi XZ, Huang LH, Shao ZL \& Guo W 2019 Liraglutide combined with human umbilical cord mesenchymal stem cell transplantation inhibits beta-cell apoptosis via mediating the ASK1/JNK/BAX pathway in rats with type 2 diabetes. Diabetes/ Metabolism Research \& Reviews 36 e3212. (https://doi.org/10.1002/ dmrr.3212)

Wang Z, York NW, Nichols CG \& Remedi MS 2014 Pancreatic beta cell dedifferentiation in diabetes and redifferentiation following insulin therapy. Cell Metabolism 19 872-882. (https://doi.org/10.1016/j. cmet.2014.03.010)

Weir GC \& Bonner-Weir S 2017 GABA signaling stimulates $\beta$ cell regeneration in diabetic mice. Cell 168 7-9. (https://doi. org/10.1016/j.cell.2016.12.006)

Xuan X, Gao F, Ma X, Huang C, Wang Y, Deng H, Wang S, Li W \& Yuan L 2018 Activation of ACE2/angiotensin (1-7) attenuates pancreatic $\beta$ cell dedifferentiation in a high-fat-diet mouse model. Metabolism: Clinical and Experimental 81 83-96. (https://doi.org/10.1016/j.metabol.2017.12.003)

Yoo DY, Kim W, Yoo KY, Nam SM, Chung JY, Yoon YS, Won MH \& Hwang IK 2012 Effects of pyridoxine on a high-fat diet-induced reduction of cell proliferation and neuroblast differentiation depend on cyclic adenosine monophosphate response element binding protein in the mouse dentate gyrus. Journal of Neuroscience Research 90 1615-1625 (https://doi.org/10.1002/jnr.23035)

Yoshihara E, Fujimoto S, Inagaki N, Okawa K, Masaki S, Yodoi J \& Masutani H 2010 Disruption of TBP-2 ameliorates insulin sensitivity and secretion without affecting obesity. Nature Communications $\mathbf{1}$ 127-138. (https://doi.org/10.1038/ncomms1127)

Yuan L, Lu CL, Wang Y, Li Y \& Li XY 2014 Ang (1-7) protects islet endothelial cells from palmitate-induced apoptosis by AKT, eNOS, p38 MAPK, and JNK pathways. Journal of Diabetes Research 2014 1-10. (https://doi.org/10.1155/2014/391476)

Yuan L, Wang Y, Lu C \& Li X 2013 Angiotensin-converting enzyme 2 deficiency aggravates glucose intolerance via impairment of islet microvascular density in mice with high-fat diet. Journal of Diabetes Research 2013 1-8. (https://doi.org/10.1155/2013/405284)

Zhou M, Wang H, Zeng X, Yin P, Zhu J, Chen W, Li X, Wang L, Wang L, Liu Y, et al. 2019 Mortality, morbidity, and risk factors in China and its provinces, 1990-2017: a systematic analysis for the Global Burden of Disease Study 2017. Lancet 2394 1-14. (doi:10.1016/S01406736(19)30427-1)

Received in final form 7 June 2020

Accepted 1 July 2020

Accepted Manuscript published online 1 July 2020 https://joe.bioscientifica.com https://doi.org/10.1530/JOE-19-0471
(C) 2020 Society for Endocrinology Published by Bioscientifica Ltd. Printed in Great Britain 